'Departamento Dermatología, Facultad de Medicina, Pontificia Universidad Católica de Chile, Santiago, Chile.

2Departamento de Anatomía Patológica, Facultad de Medicina Pontificia Universidad Católica de Chile, Santiago, Chile.

Fuente de financiamiento: grant de la liga internacional de sociedades de dermatología la cual no tuvo influencia en el diseño del estudio, ni en el análisis ni interpretación de los datos.

Recibido el 22 de julio de 2013 , aceptado el 10 de marzo de 2014.

Correspondencia a: Dra. Juana Benedetto $E$. Dirección: Servicio de Dermatólogía. Clínica Alemana de Santiago, Facultad de Medicina Clínica Alemana, Universidad del Desarrollo, Santiago, Chile. juanita.benedetto@gmail.com

\section{Búsqueda del ADN del virus HTLV-1 en biopsias de pacientes con linfoma cutáneo de células $\mathrm{T}$}

\author{
JUANA BENEDETTO E. ${ }^{1}$, MONTSERRAT MOLGÓ N. ${ }^{1}$, \\ SERGIO GONZÁLEZ B. ${ }^{2}$
}

\section{Detection of HTLV-1 DNA in biopsies of Chilean patients with cutaneous T-cell lymphoma}

Background: Human T-lymphotropic virus-1 (HTLV-1) infection has been associated with the pathogenesis of cutaneous T cell lymphomas (CTCL). Aim: To search for HTLV-1 DNA in skin biopsies of patients with CTCL. Material and Methods: A retrospective study was conducted using 25 biopsies of patients with CTCL. DNA was extracted from lymphoid tissue by microdissection. A nested $P C R$ was conducted to detect HTLV-1 genome using primers for the tax region. As negative controls, four cases of superficial perivascular dermatitis were chosen. As positive controls, five cases of T-cell leukemia/lymphoma (ATCL) were studied. Results: A positive reaction was found in 3 of 25 cases. These biopsies corresponded to a case of Mycosis Fungoides, a case of CD30 (-) T cell lymphoma and a case of lymphomatoid papulosis. Search was negative in the four cases of superficial perivascular dermatitis and positive in four cases of adult T-cell leukemia/lymphoma (ATCL). Conclusions: HTLV-1 DNA search in tissues is a useful tool recommended to study T-cell lymphomas. HTLV-1 infection only occurs in sporadic cases but may contribute to tumor aggressiveness and prognosis.

(Rev Med Chile 2014; 142: 314-322)

Key words: Human T-lymphotropic virus 1; Lymphoma, T-cell, cutaneous; Polymerase chain reaction.
L os linfomas cutáneos de células T (LCCT) corresponden a un grupo clínica e histológicamente heterogéneo de neoplasias cutáneas originadas a partir de linfocitos $\mathrm{T}^{1}$.

Según la clasificación europea (EORTC) los LCCT se agrupan, según su conducta clínica, en formas indolentes, agresivas y entidades provisorias. Dentro del primer grupo están micosis fungoide (MF) y sus variantes, linfoma de células grandes CD30 $(+)$ y papulosis linfomatoide (PL). Entre las formas agresivas se encuentra el síndrome de Sézary (SS) y el linfoma de células grandes CD30(-). Las entidades provisorias corresponden al linfoma $\mathrm{T}$ pleomórfico de células pequeñas y al linfoma $\mathrm{T}$ paniculítico ${ }^{2}$.

Los LCCT presentan etiología diversa, dentro de las cuales se encuentra el virus HTLV-1, el cual es retrovirus patogénico humano, principalmente linfotrópico que infecta linfocitos T CD4(+), células dendríticas sanguíneas y del epitelio sinovial.

Dentro de las enfermedades asociadas a infección por HTLV-1 se encuentran: leucemia-linfoma de células T del adulto (ATCL), LCCT, mielopatía asociada a HTLV-1/paraparesia espástica tropical (HAM/TSP) y dermatitis infectiva (DI).

En los LCCT, la asociación es motivo de activa búsqueda e investigación. En Estados Unidos de Norteamérica y Europa se ha encontrado una presencia variable del virus (1-12\%) mediante la técnica de reacción polimerasa en cadena (PCR) in situ ${ }^{3}$. En Alemania se ha encontrado virus en linfomas cutáneos $\mathrm{T}$ de células grandes CD30 $(+)^{4}$ en tejido fresco por Southern Blot y PCR. En Japón, se encontró presencia de HTLV-1 en MF 
y SS por técnica de hibridación in situ en tejido fijado en formalina ${ }^{5}$. También se ha aislado ADN viral en tejido tumoral, líneas celulares de pacientes con MF y en sangre periférica de familiares de pacientes con $\mathrm{MF}^{6,7}$. Otros investigadores no han detectado ADN de HTLV-1 en LCCT ${ }^{4,8-10}$.

Existe evidencia que sugiere que los pacientes con LCCT albergan tanto en los linfocitos circulantes como en los radicados en la piel, la secuencia tax del virus HTLV-1, lo cual ocurre también en sus parientes sanos y en donantes sanos ${ }^{11}$.

El virus HTLV-1 ha sido ampliamente detectado en sangre, tejido fresco y tejido fijado en formalina $^{4,5,7,8,12}$.

En sangre, la pesquisa para HTLV-1 se realiza por método de ELISA. Las técnicas confirmatorias consisten en el método de Western Blot y PCR para detectar material genético del virus. Se han usado partidores que detectan en tejido distintos genes de la estructura genómica de HTLV-1, como: gen pX (5), gen env (5), gen pol (4) y gen $\operatorname{tax}^{9,13}$.

También se puede detectar el virus en el tejido por el método de hibridación in situ.

La evaluación de la presencia de HTLV-1 en los infiltrados linfoides de estirpe $\mathrm{T}$, nos permite contar con una variable importante, necesaria y recomendada internacionalmente para realizar un acabado estudio de estos linfomas ${ }^{10}$.

La detección de HTLV-1 puede dar información sobre una relación causal o al menos facilitadora del virus en el desarrollo de LCCT, así como también para el diagnóstico diferencial histológico de los infiltrados linfoides de estirpe T.

Chile es una zona no endémica para HTLV-1, de baja prevalencia, donde no existen datos de la incidencia del virus en tejido tumoral de pacientes con LCCT.

El propósito del presente trabajo es determinar la presencia del $\mathrm{ADN}$ del virus HTLV-1 en biopsias de piel de pacientes con LCCT y comparar esos resultados con la presencia del ADN de HTLV-1 en biopsias de pacientes con ATCL y con biopsias de controles sanos no portadores del virus.

\section{Materiales y Métodos}

\section{Selección de los casos:}

Se seleccionaron 25 casos de pacientes con LCCT pertenecientes al departamento de Dermatología y Anatomía Patológica de la Pontificia
Universidad Católica de Chile. Los pacientes incluidos fueron objeto de una revisión completa de sus antecedentes clínicos e iconográficos para realizar adecuada clasificación clínica.

La histología y la inmunohistoquímica de los pacientes seleccionados fueron nuevamente revisados por dermatólogo y dermatopatólogo especialista en linfoma, con lo cual se pudo clasificar según la EORTC.

Los casos incluidos fueron: $16 \mathrm{MF}, 1 \mathrm{LCT}$ con mucinosis folicular, 1 reticulosis pagetoide, 2 papulosis linfomatoide, 4 LCT de células grandes, 1 LT paniculitis-like.

Para los controles negativos se eligieron 4 casos de dermatitis perivasculares superficiales. Los pacientes controles no dispusieron de estudio en suero para HTLV-1. Fueron elegidos por ser infiltrados linfoides parecidos a los linfomas $T$ pero con alta probabilidad de ser HTLV-1 negativos (igual que la población general).

Como controles positivos fueron seleccionados 5 casos de leucemia linfoma $\mathrm{T}$ del adulto (ATCL). El diagnóstico histológico fue confirmado por el patólogo experto; los pacientes disponían de estudio en suero para HTLV-1 positivo (ELISA y PCR).

\section{Extracción del ADN}

Las muestras se obtuvieron a partir de las preparaciones teñidas con hematoxilina eosina mediante microdisección con lupa. Se ubicó la zona del infiltrado linfocitario sospechoso y bajo visión microscópica se procedió a microdisecar el tejido. Las muestras se sometieron a centrifugación a $14.000 \mathrm{rpm}$ por $10 \mathrm{~min}$.

El ADN se extrajo por medio de una solución de extracción con proteinasa $\mathrm{K}$, Tris $1 \mathrm{M}$, Tween 20 y agua. Luego se incubaron a $37^{\circ} \mathrm{C}$ por $48 \mathrm{~h}$. Posteriormente se calentaron a $100^{\circ} \mathrm{C}$ por $10 \mathrm{~min}$ para inactivar la proteinasa $\mathrm{K}$. Posteriormente fueron mantenidas a $-20^{\circ} \mathrm{C}$ hasta su amplificación.

En casos en que hubo duda sobre la calidad de ADN extraído o de la presencia de inhibidores de amplificación, se procedió a purificar el $\mathrm{ADN}$ con el método de sílica (QiaGEN).

\section{PCR y electroforesis en gel de agarosa}

\section{PCR B-Globina}

Para el estudio de calidad de ADN y presencia de inhibidores se utilizaron partidores para el gen 
humano de B-globina de 268 pb. (P-A + P-S) y de $110 \mathrm{pb}(\mathrm{P}-110+\mathrm{P}-\mathrm{S})$.

P-A (partidor antisentido 268bp): GAA GAG CCA AGG ACA GGT AC

P-110 (partidor antisentido 110bp): ACA CAA CTG TGT TCA CTA GC

P-S (partidor sentido 268bp-110bp): CAA CTT CAT CCA CGT TCA CC

Las muestras se amplificaron para B-globina de 268 bp o $110 \mathrm{pb}$. En aquellas que resultaron negativas se purificó el ADN pasando la muestra por columna QiaGEN y luego se repitió la PCR.

\section{PCR para $H T L V-1$}

Para el estudio de búsqueda de HTLV-1 se utilizaron partidores para el gen Tax publicados por Vandamme y col. ${ }^{14}$. Estos son utilizados rutinariamente por el Laboratorio de Biología Molecular de la PUC para buscar HTLV-1 en suero de pacientes afectados.

Se realizó un PCR anidado (Nested PCR) que utiliza dos conjuntos de partidores llamados "externos" e "internos". La secuencia de ADN blanco de los partidores internos se encuentra dentro de la secuencia blanco de los partidores externos.

La muestra de tejido cutáneo se hizo correr primero con los partidores externos AV42 y AV43 (218 pb) y la segunda reacción (que utilizó como ADN blanco el producto de la primera reacción) se hizo correr con los partidores internos AV49 y AV $80(109 \mathrm{pb})^{14}$.

AV42 (sentido): CTC CCC TCC TTC CCC AC AV43 (antisentido): CCA (G/C)(A/G)(G/T) GGT GTA IAI GTT TTG G

AV49 (sentido): CCC TCC TTC CTC CAG GCC AT

AV80 (antisentido): GGT CTG GAA AAG ACA GGG TTG

Este procedimiento aumenta la sensibilidad del ensayo, reamplificando el producto de la primera reacción en la segunda reacción, y también la especificidad porque los partidores internos amplifican sólo si de la primera reacción se obtuvo un producto específico.

Se utilizaron controles negativos de tejido, y de agua (para controlar posible contaminación) y luego muestras previamente negativas, al menos uno por corrida de PCR.
Se utilizaron controles positivos para evaluar la eficiencia de la reacción usando muestras de sangre (previamente positivas) diluidas y posteriormente muestras de tejido previamente positivas de pacientes con leucemia linfoma $\mathrm{T}$, al menos una por corrida de PCR.

Para el análisis de los resultados para B-globina y para HTLV-1, las muestras se sometieron a electroforesis en gel de agarosa al $2 \%$, posteriormente se tiñeron con bromuro de etidio $0,05 \mathrm{ug} /$ $\mathrm{ml}$, y el gel fue examinado bajo luz ultravioleta de longitud de onda $302 \mathrm{~nm}$, para visualizar los productos de PCR.

Enseguida las bandas fueron fotografiadas con cámara digital (modelo Olympus) y también algunos geles fueron fotografiados con cámara instantánea marca Polaroid.

Las fotografías de los geles fueron interpretadas por los autores y por un bioquímico experto en Biología Molecular.

Para la lectura de las líneas de gel, se consideró positiva para B-globina una banda en el tamaño de 268 bp y 110 bp respectivamente.

Para el producto de amplificación de HTLV-1 se consideró positiva una banda a la altura de 109 bp en la segunda reacción de PCR.

\section{Resultados}

\section{Características de la muestra en estudio}

En la Tabla 1 se puede observar las características de los casos estudiados y sus diagnósticos. Trece correspondieron al sexo femenino (52\%) y doce a sexo masculino (48\%). El promedio de edad fue de 49,8 años.

El promedio de edad para los controles positivos fue de 45 años, todos fueron de sexo femenino. El promedio de edad para los controles negativos fue de 34 años (Tabla 2).

\section{Validación de la técnica de detección de HTLV-1}

Se estudió la calidad del ADN para los controles negativos y en todos ellos los resultados muestran positividad para B-globina de 110bp (Figura 1).

Para los casos de ACTL (controles positivos) 4 de 6 los resultados muestran positividad para B-globina. El PCR anidado para HTLV-1 (Figuras 2 y 3 ), también muestra positividad.

Cabe señalar que aquellos dos casos en que 
Búsqueda del virus HTLV-1 en biopsias de linfoma cutáneo de células T - J. Benedetto et al

Tabla 1. Características de los casos estudiados y sus diagnósticos clínicos

\begin{tabular}{|cccl|}
\hline Paciente & Sexo & Edad & Diagnóstico \\
T1 & M & 78 & $\begin{array}{l}\text { Linfoma T células grandes } \\
\text { CD30 (-) }\end{array}$ \\
\hline T2 & M & 78 & Micosis fungoide \\
\hline T3 & M & & Micosis fungoide \\
T4 & F & 19 & Micosis fungoide \\
\hline T5 & F & 58 & Linfoma T células grandes \\
T6 & F & 45 & Reticulosis pagetoide \\
\hline T7 & F & 73 & Linfoma T células grandes \\
T8 & F & 25 & Mucinosis folicular \\
\hline T9 & M & 79 & Micosis fungoide \\
\hline T10 & F & 3 & Linfoma T células grandes \\
\hline T11 & F & 23 & Linfoma T paniculítico \\
\hline T12 & F & & Micosis fungoide \\
\hline T13 & F & 25 & Micosis fungoide \\
\hline T14 & F & 20 & Micosis fungoide \\
\hline T15 & M & 56 & Micosis fungoide \\
\hline T16 & M & 73 & Micosis fungoide \\
\hline T17 & M & 64 & Micosis fungoide \\
\hline T18 & M & 77 & Micosis fungoide \\
\hline T19 & M & 50 & Micosis fungoide \\
\hline T20 & F & 30 & Micosis fungoide \\
\hline T21 & M & 64 & Micosis fungoide \\
\hline T22 & M & 70 & Micosis fungoide \\
\hline T23 & M & 33 & Micosis fungoide \\
T24 & F & 68 & Papulosis linfomatoide \\
\hline T25 & F & 35 & Papulosis linfomatoide \\
\hline & & & \\
\hline
\end{tabular}

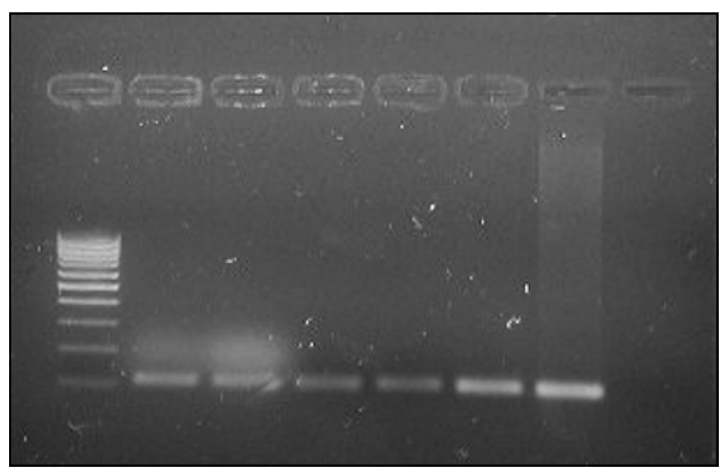

Figura 1. BG 110 para controles negativos: se aprecia que todos los controles negativos (N1, N2, N3 y N4) resultaron positivos para BG $110 \mathrm{bp}$. Carril 1 Marcador de peso molecular (100 bp), carril 2 muestra N2, carril 3 muestra N1, carril 4 muestra N4, carril 5 muestra N3, carril 6 control positivo en sangre (diluido 1: 30), carril 7 control (+) en suero directo, carril 8 control (-) (agua).

resultó negativa la PCR para HTLV-1 (C4 y C6) también lo fueron para B-globina, por tanto ello sugiere que las muestras son probablemente inhibidas sin ADN susceptible de ser analizado.

\section{Detección de HTLV-1 en los casos seleccionados}

En la Tabla 3 se observa que del total de 25 casos estudiados, 3 muestran positividad para HTLV-1, (12\%). Estos fueron: linfoma de células grandes CD30 (-) (caso T1), MF etapa placas (caso T2) y papulosis linfomatoide (caso T 24).

En el caso T1 el paciente de sexo masculino tenía demostrado HTLV-1 en sangre por Elisa y PCR. Se trató de un linfoma T CD30 (-) agresivo que presentó lesiones secundarias retroperitoneales un año después del diagnóstico (Figuras 4 y 5 ).

Tabla 2.

\begin{tabular}{|cccl|}
\hline Controles positivos & Sexo & Edad & Diagnóstico \\
C1 & F & 38 & Leucemia linfoma T del adulto \\
C2 & F & 48 & Leucemia linfoma T del adulto \\
C3 & F & 47 & Leucemia linfoma T del adulto \\
C4 & F & 47 & Leucemia linfoma T del adulto \\
C5 & F & 52 & Leucemia linfoma T del adulto \\
C6 & F & 38 & Leucemia linfoma T del adulto \\
Controles negativos & Sexo & Edad & Diagnóstico \\
N1 & F & 39 & Dermatitis perivascular superficial espongiotica \\
N2 & M & 45 & Dermatitis perivascular superficial espongiotica \\
N3 & F & 12 & Dermatitis perivascular superficial espongiotica \\
N4 & F & 40 & Dermatitis perivascular superficial espongiotica \\
\hline
\end{tabular}




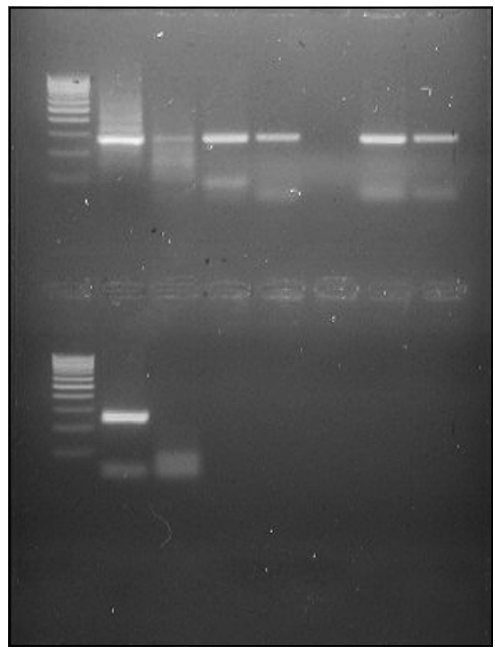

Figura 2. B globina 268 para controles positivos: se aprecia que todos los casos menos C4 y C6 dieron positivo para BG 268. Carril 1: Marcador de peso molecular (100 bp), carril 2: control positivo en suero, carril 3: caso C4, carril 4: caso C3, carril 5: caso C1, carril 6: caso C6, carril 7: caso C5, carril 8: caso C7, carril 9: marcador de paso molecular, carril10: control positivo en suero, carril 11: control negativo.

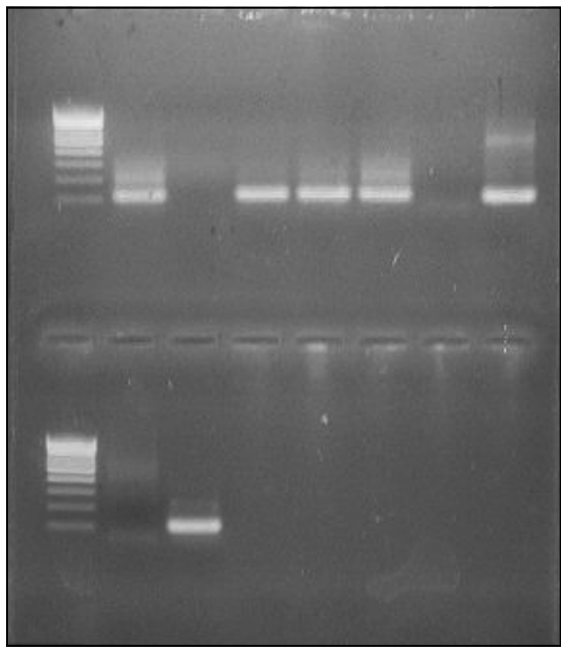

Figura 3. HTLV-1 para controles positivos (banda a $109 \mathrm{pb}$ ): se aprecia que todos los casos menos C4 y C6 dieron positivos para la secuencia tax de HTLV1. Carril 1: Marcador de peso molecular (100 bp), carril 2: caso C1, carril 3: caso C6, carril 4 caso C2, carril 5: caso C3, carril 6 : caso C5, carril 7: caso C4, carril 8: control positivo en suero 1/10, carril 9: marcador de peso molecular, carril 10: control negativo agua, carril 11: control positivo $1 / 10.000$.

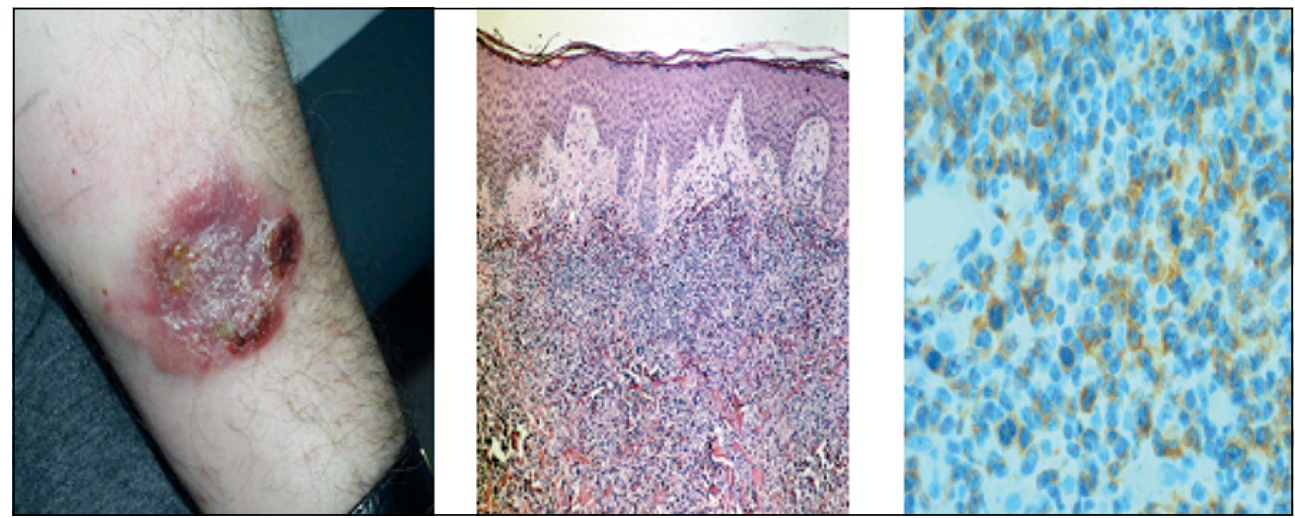

Figura 4. Foto clínica e histológica de caso T1. (A) Se aprecia masa tumoral de color rojo vinoso, bordes solevantados y centro ulcerado en antebrazo izquierdo. (B) infiltración dérmica tumoral Infiltración dérmica por tumor de células grandes CD30 (-), con marcado pleomorfismo celular, atipías y mitosis. (C) El infiltrado expresa el marcador CD25.

El caso T2 (MF) fue un paciente de 78 años que al ser revisado retrospectivamente no recibió tratamiento ni se estudió la presencia de HTLV-1 en sangre (Figura 6).

El caso T24 es un paciente de sexo femenino de 68 años con papulosis linfomatoide que se trató exitosamente con puvaterapia y presenta brotes ocasionales de lesiones (Figura 7).
En 22 casos de linfoma cutáneo los resultados de la técnica muestran negatividad para HTLV 1. En 11 de estos caso de linfoma se demostró calidad de ADN por B-globina 268 y en 14 de ellos por B-globina 110. De modo que todos los casos tuvieron ADN susceptible de analizar. En la Tabla 3 se demuestra un análisis de calidad de ADN para algunos casos. 


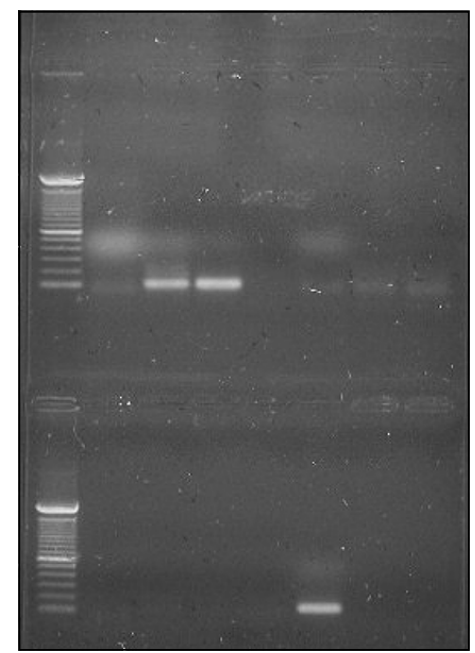

Figura 5. Positividad de LT CD30 (-) para HTLV-1 (caso T1), banda a $110 \mathrm{pb}$. Se aprecia en el carril 2 y 3 que dos muestras de T1 resultaron positivas para HTLV-1. El resto de los casos resultó negativo. Carril 1: marcador de peso de peso molecular, carril 2: control negativo en tejido (N1), carril 3: caso T1 (muestra a), carril 4: caso T1 (muestra b), carril 5: caso T9, carril 6: caso T4, carril 7: caso T3, carril 8: caso T9, carril 9: caso T5, carril10: caso T6, carril 11: caso T7, carril 12: caso T8, carril 13: control positivo en tejido (C2).

\section{Discusión}

En relación a la búsqueda HTLV-1 en biopsias de linfomas cutáneos $\mathrm{T}$, nuestros resultados concuerdan con los publicados en la literatura, en que en la mayoría de los infiltrados de LCCT no se logró evidenciar la presencia de HTLV-1 ${ }^{7-9}$.

Sin embargo, al igual que en Japón, Estados Unidos de Norteamérica y Europa es posible observar casos de LCCT con presencia de HTLV-1. En nuestro estudio encontramos un caso de linfoma T CD30 (-), un caso de MF y uno de papulosis linfomatoide.

Todos nuestros controles de ATCL los resultados mostraron positividad para HTLV-1 en la biopsia, lo que demuestra la calidad técnica del PCR. Se ha observado también que la presencia del genoma del HTLV-1 es una condición necesaria en la producción de la leucemia-linfoma T.

Si bien la PCR para HTLV-1 positiva sugiere la presencia del virus en la biopsia, no informa sobre el tipo de célula infectada por el virus. Para ello sería necesario complementar este estudio con técnicas como la hibridación in situ que permite

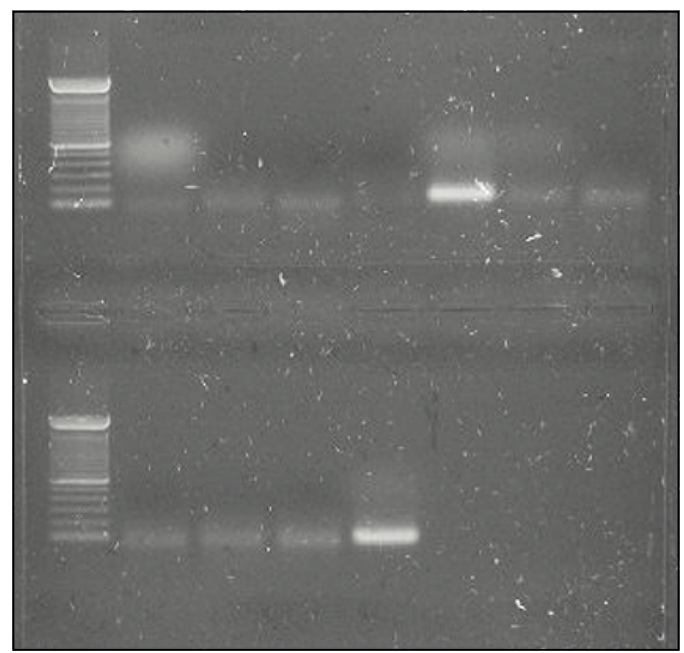

Figura 6. Positividad de MF (caso T2), carril 6, para HTLV-1. Carril 1: marcador de peso molecular, carril 2: control negativo en tejido (N1), carril 3: T8, carril 4: T10, carril 5: T11, carril 6: T2 (muestra a), carril 7: T3, carril 8: T2 (muestra b), carril 9: control peso molecular, carril 10: T8, carril 10: T10, xarril 11: control agua, carril 12: control positivo en tejido (C2).

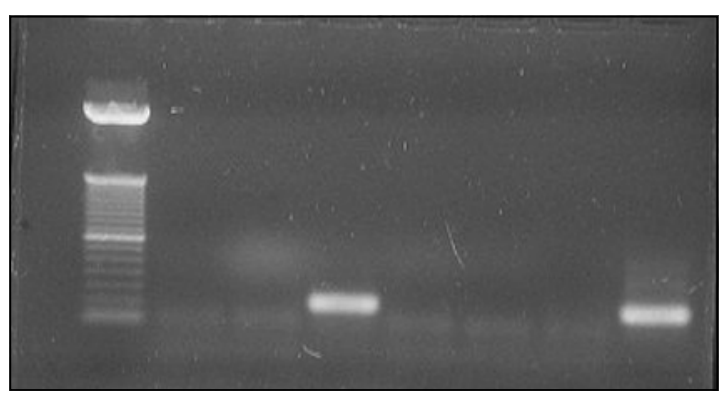

Figura 7. Positividad de papulosis linfomatoide (T24), carril 6, para HTLV-1. Carril 1: marcador de peso molecular, carril 2: control negativo en tejido (N4), carril 3: T17, carril 4: T24, carril 5: T15, carril 6: T2 (muestra a), carril 7: T2 (muestra b), carril 8: control positivo en tejido (C1).

demostrar el virus al interior de las células. Es razonable inferir que las células infectadas son los linfocitos T CD4(+) presentes en el infiltrado linfoide si bien hay estudios que muestran también integración viral en queratinocitos ${ }^{15}$.

Es probable que la proporción de linfomas cutáneos en los que se encuentre el virus dependa además de la prevalencia de la infección por HTLV-1 en un territorio determinado. En Perú, por ejemplo, en áreas endémicas alrededor de $20 \%$ de los linfomas T cutáneos son HTIV-1 positivos ${ }^{16}$. 
Búsqueda del virus HTLV-1 en biopsias de linfoma cutáneo de células T - J. Benedetto et al

Tabla 3. Estudio de búsqueda de HTLV-1 en biopsias de Linfoma cutáneo de células T

\begin{tabular}{|c|c|c|c|c|}
\hline Paciente & Diagnóstico & BG110 & BG 268 & HTLV-1 \\
\hline C1 & Leucemia linfoma T del adulto & & $\mathrm{SI}$ & $\mathrm{SI}$ \\
\hline C2 & Leucemia linfoma T del adulto & & $\mathrm{SI}$ & $\mathrm{SI}$ \\
\hline C3 & Leucemia linfoma T del adulto & & SI & SI \\
\hline C4 & Leucemia linfoma T del adulto & & NO & NO \\
\hline C5 & Leucemia linfoma T del adulto & & $\mathrm{SI}$ & $\mathrm{SI}$ \\
\hline C6 & Leucemia linfoma T del adulto & & NO & NO \\
\hline N1 & Dermatitis perivascular superficial espongiótica & SI & & NO \\
\hline N2 & Dermatitis perivascular superficial espongiótica & SI & & NO \\
\hline N3 & Dermatitis perivascular superficial espongiótica & SI & & NO \\
\hline N4 & Dermatitis perivascular superficial espongiótica & SI & & NO \\
\hline $\mathrm{T} 1$ & Linfoma T células grandes CD30 (-) & & SI & SI \\
\hline T2 & Micosis fungoides & SI & NO & SI \\
\hline T3 & Micosis fungoides poiquilodermatosa & SI & & NO \\
\hline T4 & Micosis fungoide & & SI & NO \\
\hline T5 & Linfoma T células grandes & & SI & NO \\
\hline T6 & Reticulosis pagetoide & $\mathrm{SI}$ & & NO \\
\hline $\mathrm{T} 7$ & Linfoma T células grandes & SI & & NO \\
\hline T8 & Mucinosis folicular & & SI & NO \\
\hline T9 & Micosis fungoides & $\mathrm{SI}$ & & NO \\
\hline $\mathrm{T} 10$ & Linfoma T células grandes & $\mathrm{SI}$ & NO & NO \\
\hline T11 & Linfoma T paniculítico & SI & & NO \\
\hline $\mathrm{T} 12$ & Micosis fungoide & $\mathrm{SI}$ & & NO \\
\hline $\mathrm{T} 13$ & Micosis fungoide & SI & & NO \\
\hline T14 & Micosis fungoide & SI & & NO \\
\hline T15 & Micosis fungoide & $\mathrm{SI}$ & & NO \\
\hline T16 & Micosis fungoide & $\mathrm{SI}$ & & NO \\
\hline $\mathrm{T} 17$ & Micosis fungoide & & SI & NO \\
\hline $\mathrm{T} 18$ & Micosis fungoide & & SI & NO \\
\hline T19 & Micosis fungoide & & SI & NO \\
\hline T20 & Micosis fungoide & & SI & NO \\
\hline $\mathrm{T} 21$ & Micosis fungoide & & $\mathrm{SI}$ & NO \\
\hline $\mathrm{T} 22$ & Micosis fungoide & $\mathrm{SI}$ & & NO \\
\hline $\mathrm{T} 23$ & Micosis fungoide & & $\mathrm{SI}$ & NO \\
\hline T24 & Papulosis linfomatoide & & SI & SI \\
\hline T25 & Papulosis linfomatoide & SI & & NO \\
\hline
\end{tabular}


En Chile, que es un territorio de baja prevalencia, la proporción de linfomas infectados coincide con las de zonas similares en prevalencia como Europa y Estados Unidos de Norteamérica.

No es descartable sin embargo, que en los casos con resultado positivo para HTLV-1 la presencia del virus pueda jugar un rol de significado pronóstico respecto a la agresividad del tumor, por ejemplo inhibiendo la apoptosis y antioncogenes en las células transformadas.

Es recomendable incluir la búsqueda de este virus en la lesiones proliferativas de estirpe $\mathrm{T}$, pues su presencia influye en el pronóstico y seguimiento de estos pacientes. Su búsqueda ayudaría a realizar el diagnóstico diferencial entre LCCT con formas cutáneas iniciales de ATCL, en que los hallazgos morfológicos pueden ser inespecíficos.

Es interesante notar que el mismo conjunto de partidores y la misma técnica que se usa rutinariamente en estos pacientes para detectar HTLV-1 en suero, es el que se usó para detectar la presencia del virus en el tejido.

El caso de LT CD30 (-) cuyo resultado fue HTLV1(+) en tejido, lo fue también en sangre. El caso de MF no se realizó estudio en sangre. Ello sugiere que si el paciente tiene presencia del virus demostrada por PCR en sus linfocitos circulantes, es muy probable que el infiltrado linfoide patológico también tenga presencia del virus y es razonable pensar que éste tenga un rol patogénico en la enfermedad.

Respecto a la extracción de ADN, vemos que el material fijado en formalina representa un ADN excelente calidad. Aunque su nivel de preservación es menor que el del tejido fresco, se pudo amplificar fragmentos de 268 y 110 pares de base.

Así, con una buena calidad de ADN y una técnica lo suficientemente sensible, es poco probable que hallamos obtenido falsos negativos.

Los resultados de la búsqueda de HTLV-1 en biopsias infiltrados $\mathrm{T}$ son una herramienta más para la mejor categorización de los pacientes, pero deben ser siempre interpretados en el contexto clínico. Si bien la presencia del virus se ha relacionado las enfermedades ya descritas, hay muchos pacientes portadores del virus que no desarrollan enfermedades infiltrativas $\mathrm{T} y$ permanecen como portadores.

En conclusión, la búsqueda de HTLV-1 en linfomas de células $\mathrm{T}$ es un elemento de utilidad para el análisis de los infiltrados linfoides de estirpe T, ya que ayuda en su categorización y seguimiento.

En Chile, país de baja prevalencia de la infección por HTLV-1, no se había estudiado la presencia del ADN viral en biopsias de pacientes con linfomas cutáneos. Nuestros resultados concuerdan con lo publicado en la literatura, en los que la mayoría de los infiltrados de LCCT no evidencia presencia de HTLV-1. Por ello consideramos un aporte caracterizar el comportamiento de este virus y sus enfermedades asociadas en nuestro país.

\section{Referencias}

1. Heald P, Latkowski J. Cutaneous T Cell Lymphomas En: Freedberg I, Eisen A, Wolf K, et al. Dermatology in General Medicine Sexta Edición 2003, Nueva York: 1537-58.

2. Willemze R, Kerl H, Sterry W, Berti E, Cerroni L, Chimenti $\mathrm{S}$, et al. EORTC Classification for primary cutaneous lymphomas: a proposal from the cutaneous lymphoma study group of the european organization for research and treatment of cancer. Blood 1997; 90 (1): 354-71.

3. Zucker-Franklin. The role of human T cell lymphotropic virus type 1 tax in the development of cutaneous $\mathrm{T}$ cell lymphoma. Annals of the New York Academy of Sciences 2001; 941: 86-96.

4. Anagnostopoulos I, Hummel M, Kaudewitz P, Herbst H, Braun Falco O, Stein H, et al. Detection of HTLV-1 proviral sequences in CD30-positive large cell cutaneous T-cell lymphomas. Am J Pathol 1990; 137 (6): 1317-22.

5. Chang YT, Liu HN , Chen CL, Chow KC. Detection of Epstein-Barr Virus and HTLV-1 in T-cell lymphomas in Taiwan. Am J Dermatopathol 1998; 20 (3): 250-4.

6. Ghosh SK, Abrams JT, Terunuma H,Vonderheld EC, De Freitas E. Human T-cell leucemia virus type I Tax/Rex DNA and RNA in cutaneous T cell lymphoma: Blood 1994; 84 (8): 2663-71.

7. Zucker-Franklin D, Pancake BA, Marmor M, Legier PM. Reeexamination of human $\mathrm{T}$ cell lumphotropic virus (HTLV I/II) prevalence. Proc Natl Acad Sci USA1997; 94 (12): 6403-7.

8. Kikuchi A, Nishikawa T, Ikeda Y, Yamaguchi K. Absence of human T-lymphotropic virus tipe I in japanese patients with cutaneous T-cell lymphoma. Blood 1997; 89 (5): 1529-32.

9. Boni R, Davis Daneshfar A, Burg G, Fuchs D, Wood GS. No detection of HTLV-1 proviral DNA in lesional skin biopsies from swiss and german patients with cutaneous T-cell lymphoma. British Journal of Dermatology 1996; 134: 282-4. 
Búsqueda del virus HTLV-1 en biopsias de linfoma cutáneo de células T - J. Benedetto et al

10. Noorali S, Yaqoob N, Nasir M, Moatter T, Pervez S. Prevalence of mycosis fungoides and its association with EBV and HTLV-1 in Pakistanian patients. Pathology Oncology Research 2002; 8 (3): 194-9.

11. Primo JR, Brite C, Oliveira M de F, Moreno-Carvalho O, Machado M, Bittencourt AL. Infective dermatitis and human $\mathrm{T}$ cell lymphotropic virus type 1-associated myelopathy/ tropical spastic paraparesia in childhood and adolescence. Clinical Infectious Disease 2005; 41 (4): 535-41.

12. Arai E, Chow K, Li CY, Tokunaga M, Katayama I. Differentiation between cutaneous form of adult $\mathrm{T}$ cell leucemia/lymphoma and cutaneous $\mathrm{T}$ cell lymphoma by in situ hybridation using a human $\mathrm{T}$ cell leukemia virus-1 DNA probe. Am J Pathol 1994; 144 (1): 15-20.

13. Incan $\mathrm{M}$, Antoniotti $\mathrm{O}$, Gasmi $\mathrm{M}$, Fonck $\mathrm{Y}$, Chassagne J, Desgranges C, Souteyrand P. HTLV-1-asoociated lymphoma presenting as mycosis fungoides in an HTLV-1 non-endemic area: a viro molecular study. British Journal of Dermatology 1995; 132 (6): 983-8.

14. Vandamme AM, Laethem KV, Liu HF, Van Brussel M, Delaporte E, De Castro Costa C, et al. Use of a generic polymerase chain reaction assay detecting human $\mathrm{T}$ lymphotropic virus (HTLV) types I, II and divergent simian strains in the evaluation of individuals with indeterminate HTLV serology. Journal of Medical Virology 1997; 52 (1): 1-7.

15. Zucker-Franklin D. The role of human T cell lymphotropic virus type 1 tax in the development of cutaneous T cell lymphoma. Annals of the New York Academy of Sciences 2001; 941: 86-96.

16. Bravo F, Sánchez MR. New and emerging cutaneous in- fectious diseases in Latin América and other geographic areas. Dermatol Clin 2003; 21 (4): 655-68.

17. Poiesz BJ, Ruscetti FW, Gazdar AF, Bunn PA, Minna JD, Gallo RC. Isolation of a new type $\mathrm{C}$ retrovirus particles from fresh and cultured lymphocytes of a patient with cutaneous T cell lymphoma. Proc Natl Sci 77 (12): 74159.

18. Barmak K, Harhaj E, Grant C. Alefantes T, Wigdahi B. Human $\mathrm{T}$ cell leucemia virus type I- induced disease: pathways to cancer and neurodegeneration. Virology 2003; 308 (1): 1-12.

19. Cartier L, Tajima K, Araya F, Castillo JL, Zaninovic V, Hayami M, et al. Estudio preliminar de seroprevalencia de HTLV-1 en población indígena chilena. Rev Med Chile 1993; 121: 241-6.

20. Suárez M, Quero M, Ramírez E. Prevalencia de anticuerpos anti HTLV-1 y posibles factores de riesgo en prostitutas chilenas. Rev Med Chile 1993; 121 (3): 614-7.

21. Sun S, Yamaoka S. Activation of NF-kB by HTLV-1 and implications for cell transformation. Oncogene 2005; 24 (39): 5952-64.

22. Grassmann R, Aboud M, Jeang KT. Molecular mechanisms of cellular transformation by HTLV-1 Tax. Oncogene 2005; 24 (39): 5976-85.

23. Marriott SJ, Semmes OJ. Impact of HTLV-1 tax on cell cycle progression and the cellular DNA damage repair response. Oncogene 2005; 24 (39): 5986-95.

24. Lupi O, Tyring SK. Tropical Dermatology: viral tropical diseases. J Am Acad Dermatol 2003; 49 (6): 979-1000.

25. Willemze R, Jaffe ES, Burg G, Cerroni L, Berti E, Swerdlow $\mathrm{SH}$, et al. WHO-EORTC classification for cutaneous lymphomas. Blood 2005; 105 (10): 3768-83. 